\title{
Class Cariacotrichea, a novel ciliate taxon from the anoxic Cariaco Basin, Venezuela
}

\author{
William Orsi, ${ }^{1}$ Virginia Edgcomb, ${ }^{2} \dagger$ Jose Faria, ${ }^{3} \dagger$ Wilhelm Foissner, ${ }^{4} \dagger \ddagger$ \\ William H. Fowle, ${ }^{1} \dagger$ Tine Hohmann, ${ }^{1} \dagger$ Paula Suarez, ${ }^{3} \dagger$ Craig Taylor, ${ }^{2} \dagger$ \\ Gordon T. Taylor, ${ }^{5} \dagger$ Peter Vd'ačný ${ }^{6} \dagger$ and Slava S. Epstein ${ }^{1} \ddagger$ \\ ${ }^{1}$ Department of Biology, Northeastern University, 313 Mugar Building, Boston, MA 02115, USA \\ ${ }^{2}$ Department of Geology and Geophysics, Woods Hole Oceanographic Institution, Woods Hole, \\ MA 02543, USA \\ ${ }^{3}$ Departamento de Biología de Organismos, Universidad Simón Bolívar, Sartenejas, Baruta, \\ Estado Miranda, Venezuela \\ ${ }^{4}$ Department of Organismal Biology, University of Salzburg, Hellbrunnerstrasse 34, Salzburg, \\ A 5020, Austria \\ ${ }^{5}$ Marine Sciences Research Center, State University of New York, Stony Brook, NY 11794, USA \\ ${ }^{6}$ Department of Zoology, Comenius University, Mlynská dolina B-1, Bratislava, SK 84215, \\ Slovak Republic
}

Correspondence Wilhelm Foissner wilhelm.foissner@sbg.ac.at Slava S. Epstein s.epstein@neu.edu

\section{INTRODUCTION}

Ciliates are highly differentiated and specialized microbial eukaryotes. The most widely recognized unifying trait of ciliates is dimorphic nuclei, namely a large macronucleus accompanied by a small micronucleus. A further characteristic feature is a large number of cilia that are present at least in some stage(s) of their life cycle. Ciliates occur across almost every habitat on Earth, from inside ice and the deep-sea to internal organs of animals (Lynn, 2008). After over 200 years of research on their diversity, morphology, physiology and evolution, the discovery of new ciliate taxa continues (Foissner et al., 2002; Song et al., 2009).

†These authors are listed in alphabetical order.

$\ddagger$ These authors contributed equally to this work.

Abbreviations: FISH, fluorescent in situ hybridization; SEM, scanning electron microscopy.

A supplementary movie is available with the online version of this paper.
The application of the rRNA approach to environmental samples suggests the presence of an enormous 'unseen' diversity of micro-organisms including ciliates (Epstein \& Lopez-Garcia, 2008). Anoxic environments in particular have been shown to house a diverse assemblage of microbial eukaryotes of high phylogenetic novelty (e.g. Stoeck et al., 2003a; Edgcomb et al., 2002; Alexander et al., 2009) but for the majority of these clades there exists no morphological data. The Cariaco Basin is the largest marine anoxic basin in the world exhibiting numerous geochemical gradients within the redox transition zone (Taylor et al., 2001), below which many novel lineages of $18 \mathrm{~S}$ rRNA genes have been detected, at different levels of taxonomic affiliation, from species to classes (Orsi et al., 2011; Stoeck et al., 2003a, 2006). In 2003, one of these clades, designated previously as CAR_H (Stoeck et al., 2003a), was discovered to be affiliated with the ciliates and phylogenetically distinct from all of the described classes. Such a high level of phylogenetic novelty is remarkable considering the widespread belief that ciliates are the best 
studied protistan phylum, such that its species have been mostly discovered (Finlay et al., 1996; but see Foissner et al., 2008 for discussion). This prompted us to visualize the cells of the CAR_H clade. Conventional silver staining-based methods for proper species description require a significant number of specimens and could not be used here: the natural abundance of CAR_H cells is low and our attempts to cultivate them were not successful. However, we were able to obtain specimens by fixing the cells in situ using a specially modified deep-sea sampler (Taylor \& Doherty, 1990; Edgcomb et al., 2011b). This provided a means to detect and visualize the cells of interest using a combined fluorescent in situ hybridization (FISH)/scanning electron microscopy (SEM) approach developed by our group (Stoeck et al., 2003b). Analyses of SEM images of the CAR_H cells show that they retain a unique feature not yet seen in any known ciliate, an archway-shaped kinety extending the whole body length and surrounding the oral opening. This feature supports the level of novelty implied by sequence data. We suggest that the ciliates from the CAR_H clade be considered as a novel taxon, Cariacotrichea nov. cl., that corresponds to a new, class-level group of ciliates.

\section{METHODS}

Sampling site. The sampling site was located in the eastern portion of the Cariaco Basin located at $10.50^{\circ} \mathrm{N} 64.66^{\circ} \mathrm{W}$. This is the location of a microbial observatory established there in 2005 (Edgcomb et al., 2011a, b; Orsi et al., 2011) and the time series station of the cooperative US-Venezuelan Carbon Retention in a Colored Ocean (CARIACO) program (Taylor et al., 2001; Muller-Karger et al., 2001). Samples were taken aboard the R/V Hermano Ginés operated by Estación de Investigaciones Marinas (EDIMAR), Fundación la Salle de Ciencias Naturales, located on Margarita Island, Venezuela.

Sample collection and fixation. Samples for FISH-SEM were taken in January 2009. The position of the oxic/anoxic interface in the water column was determined just prior to sample collection using a CTD scanner equipped with a YSI oxygen probe (Sea-Bird electronics) mounted on a Niskin rosette (General Oceanics). The location of the interface was defined as the depth at which the oxygen concentration dropped to zero. At the time of sampling, this depth was $250 \mathrm{~m}$. Samples for FISH-SEM were taken from a depth of $900 \mathrm{~m}$ using a large sample volume submersible incubation device (LV-SID) in situ water column sampler (Taylor \& Doherty, 1990; Taylor et al., 1993), which allows for sample fixation at the point of sampling. The LVSID sample collection chambers were prefilled with a mixture of Bouin's fixative and glutaraldehyde. The volume of the fixative was such that the final concentration of the fixed sample would contain $0.2 \%$ glutaraldehyde and $50 \%$ Bouin's fixative. The LV-SID was programmed on deck to take a 41 sample of water at $900 \mathrm{~m}$, to be mixed in situ with the pre-loaded fixative. Fixed samples were transferred on deck to a 41 carboy, stored at $4{ }^{\circ} \mathrm{C}$ and processed within $24 \mathrm{~h}$ at the EDIMAR shore lab on Margarita Island.

Probe design, evaluation and optimization. We designed a FISH probe, CARH658 (5'-UACUGAUACCCCCGACUGUUUC-3', 22 nt, G + C content 59\%), to target a CAR_H 18S rRNA gene sequence, BCB5F14RJ2E06 (GenBank accession no. GU819615), discovered in our recent survey of the Cariaco Basin (Edgcomb et al., 2011a, b). The probe-binding site was located using the Probe Design tool available in the ARB software package (Ludwig et al., 2004). The location of the hybridization region is within the most accessible portion of the $18 \mathrm{~S}$ rRNA gene (positions 658-680 of accession no. GU819615) based on Saccharomyces cerevisiae secondary structure (Behrens et al., 2003). The CARH658 probe is unique to the target clade as confirmed by comparing its sequence to the GenBank-nt database using BLASTN and the ARB-SILVA database using the Probe Match tool. Allowing for one to four mismatches, we identified in the public databases only one uncultivated (anaerobic ciliate Epalxella antiquorum; GenBank accession no. EF014286) and no cultivated protists. The closest cultivated species available to test the specificity of the probe is Chlamydomonas monadina, which exhibits five mismatches to the CARH658 probe. A culture of Chlamydomonas monadina was obtained and fixed (50\% Bouin's fixative, $0.2 \%$ glutaraldehyde) for use in a negative control experiment in order to optimize hybridization parameters for the probe. A range of $0-40 \%$ formamide in the hybridization buffer as well as incubations ranging from $2-4 \mathrm{~h}$ were tested to determine the stringency required to eliminate visible non-specific binding of the CARH658 FISH probe. The set of incubation parameters that produced the lowest amount of FISH signal with Chlamydomonas monadina was chosen for use with environmental samples to detect ciliates from the CAR_H clade. In a two-hour incubation using $40 \%$ formamide at $46{ }^{\circ} \mathrm{C}$, the fluorescence from the CARH658 probe was equal to that of the nonsense probe when used with the fixed culture of Chlamydomonas monadina (Fig. 1). Thus, we used these hybridization parameters in FISH-SEM for the detection of Cariacothrix caudata nov. spec.

To confirm the phylogenetic separation of the CAR_H clade from all ciliate classes and those species that appear similar to members of the CAR_H clade, the 18S rRNA gene sequence BCB5F14RJ2E06 was added to a sequence alignment incorporating representatives from all ciliate classes and ciliates morphologically similar to CAR_H cells. Only sites that could be reliably aligned were included in subsequent phylogenetic analyses. Sequences were aligned using the FASTAligner function in ARB (Ludwig et al., 2004), and alignments were then
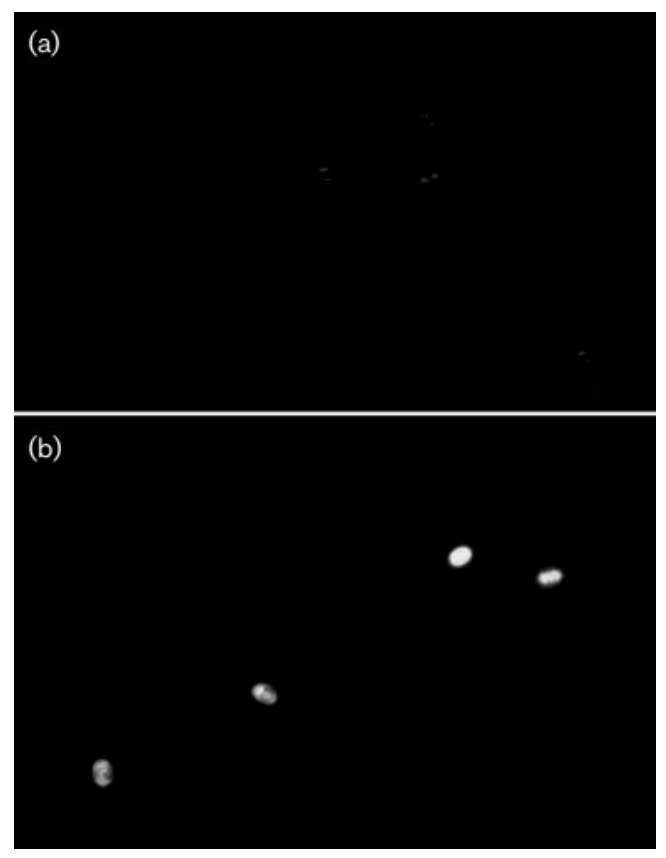

Fig. 1. Application of the probe CARH658 (a; lack of hybridization) and a universal eukaryotic probe Euk1209R ( $b$; presence of hybridization) to a fixed culture of Chlamydomonas monadina. 
manually refined. Alignments of the original sequences, along with GenBank reference sequences, were analysed using Bayesian and maximum-likelihood inference methods using RAxML (Stamatakis et al., 2008) and MrBayes (Ronquist \& Huelsenbeck, 2003). Due to missing sequence information at the $5^{\prime}$ end of many CAR_H-related sequences, non-CAR_H sequences were truncated in the alignment to match this shorter length. Phylogenetic analyses were performed on the CIPRES portal (www.phylo.org) under the GTR +I+Gamma model. The model of evolution for phylogenetic analyses was chosen using ModelTest (Posada \& Crandall, 1998). The reliability of the maximum-likelihood tree was assessed using 1000 bootstrap replicates. The Bayesian analysis consisted of two independent runs with $5 \times 10^{6}$ generations. Trees were sampled every 1000 generations with $25 \%$ discarded as burn-in. Topologies of maximum-likelihood and Bayesian trees were compared and the tree with the best log-likelihood was chosen for presentation.

FISH-SEM and SEM preparation. Samples fixed in situ for FISHSEM were processed within $24 \mathrm{~h}$ according to the protocol developed by Stoeck et al. (2003b), with some minor modifications. In short, fixed samples were filtered onto $0.4 \mu \mathrm{m}$ polycarbonate transwell membrane filters (Corning Life Sciences) and washed with $1 \times$ PBS $(\mathrm{pH}$ 7.4). PBS was gradually replaced during three cycles of bringing the volume of liquid covering the filter down to $500 \mu$ followed by adding $3 \mathrm{ml}$ hybridization buffer containing $40 \%$ formamide. After washing, $500 \mu$ l Cy3 labelled probe CARH658 $\left(30 \mathrm{ng}^{-1} \mathrm{l}^{-1}\right.$ ) was added to $3 \mathrm{ml}$ fresh hybridization buffer that covered the membrane. Transwells were incubated at $46{ }^{\circ} \mathrm{C}$ for $2 \mathrm{~h}$ in the dark, followed by incubation with a washing buffer preheated to $48{ }^{\circ} \mathrm{C}$ for $10 \mathrm{~min}$, and washing with distilled water. Transwells were then taken through a dehydration series in preparation for SEM and fixed with $100 \%$ hexamethyldisilizane (Electron Microscopy Sciences) before airdrying. As specifically noted by Stoeck et al. (2003b), it was critical not to expose the transwell filters to air at any point during the protocol, until this final step, as such exposure would have caused most fixed protists to collapse. The entire procedure was completed within $24 \mathrm{~h}$ after sampling, and the air-dried transwell filters were wrapped in aluminium foil and shipped back to the USA at $4{ }^{\circ} \mathrm{C}$. Upon arrival they were immediately placed in a $-20{ }^{\circ} \mathrm{C}$ freezer until further processing.

For comparison, ordinary SEM preparations were made, following the method of Foissner (1991). However, cells were deciliated with a detergent, as described by Foissner (2003).

Fluorescence microscopy and SEM. FISH-SEM prepared filters were cut out of the transwells using a scalpel and placed on a glass slide for visualization via epifluorescence. All filters were examined with dry objectives, as using immersion oil would have precluded the use of SEM. Filters were first scanned at $200 \times$ under appropriate illumination using a Zeiss AxioPlan 2 epifluorescence microscope equipped with a $\mathrm{HBO} 100 \mathrm{~W}$ mercury bulb; $10 \times$ Neofluar, $20 \times$ Neofluar and $40 \times$ (dry) Neofluar objectives; $10 \times$ eye pieces; DAPI and Cy3 filter sets; and a Hamamatsu CCD camera. Photographs of positively Cy3 labelled cells were taken at $400 \times$. The position of such cells was then marked for downstream (SEM) observations by making puncture marks with tweezers in the filter next to the cell's location. A minimum of three different punctures around the cell was needed to facilitate finding the labelled cell under SEM. The filter was then mounted onto a SEM specimen holder with a carbon adhesive tab and sputter coated with $10-15 \mathrm{~nm}$ of a mixture of platinum and palladium with a Tousimis Samsputter 2A (Tousimis Research Corporation). SEM was performed on a Hitachi S-4800 scanning electron microscope. Approximate location of the marked cell was achieved under low-magnification mode by finding the puncture marks in the filter. The exact location of the cell was then determined in reference to the previously noted position of the cell (during epifluorescence microscopy) in relation to the puncture marks. High magnification mode was used to take detailed photographs of the Cy3 labelled cells for morphological assessments. For creation of the film (see Movie S1, available in IJSEM Online), a Cy3 labelled cell was photographed multiple times, rotating the specimen one degree for each subsequent photo. The resulting photographs were imported into ImageJ (Abramoff et al., 2004) and exported as a Quicktime movie file (Movie S1).

\section{RESULTS}

\section{Taxonomic description}

Class Cariacotrichea nov. cl.

Diagnosis. Small, anaerobic Ciliophora with an archwayshaped kinety surrounding the oral opening and extending to posterior body end; contain a rRNA gene exhibiting $88 \%$ sequence similarity with the closest related rRNA sequence from the described species Amphisiella magnigranulosa (GenBank accession no. AM412774); contain a unique molecular signature 'GAAACAGUCGGGGGUAUCAGUA' (spanning nucleotide positions 283-305 of GenBank accession no. GU819615).

Type order. Cariacotrichida nov. ord.

\section{Order Cariacotrichida nov. ord.}

Diagnosis. Cariacotrichea with oral apparatus in anterior body half. At least two adoral organelles.

Type family. Cariacotrichidae nov. fam.

\section{Family Cariacotrichidae nov. fam.}

Diagnosis. Cariacotrichida with one adoral organelle in left posterior corner of oral cavity.

Type genus. Cariacothrix nov. gen.

\section{Genus Cariacothrix.}

Diagnosis. As for family.

Type species. Cariacothrix caudata nov. spec.

Etymology. Composite of the acronym CARIACO (for both the geographical name of the region and the multiinstitutional ocean time series project Carbon Retention In A Colored Ocean) and the Greek noun thrix (hair, cilium). Feminine gender.

\section{Cariacothrix caudata nov. spec.}

Diagnosis. FISH-SEM cells about $26 \times 10 \mu \mathrm{m}$ in size. Body ellipsoidal with flattened, slightly rostrate anterior (oral) region. About 8 ciliary rows and two distinctly elongated caudal cilia.

Type locality. Anoxic, sulfidic water column (900 m depth) of the Cariaco Basin, Venezuela, $10^{\circ} 50^{\prime} \mathrm{N} 64^{\circ} 66^{\prime} \mathrm{W}$.

Etymology. The epithet refers to the conspicuous caudal cilia.

Type material. SEM prepared filters containing in situ samples from the deep anoxic portion of the Cariaco Basin. SEM stubs containing Cariacotrichea specimens have been 

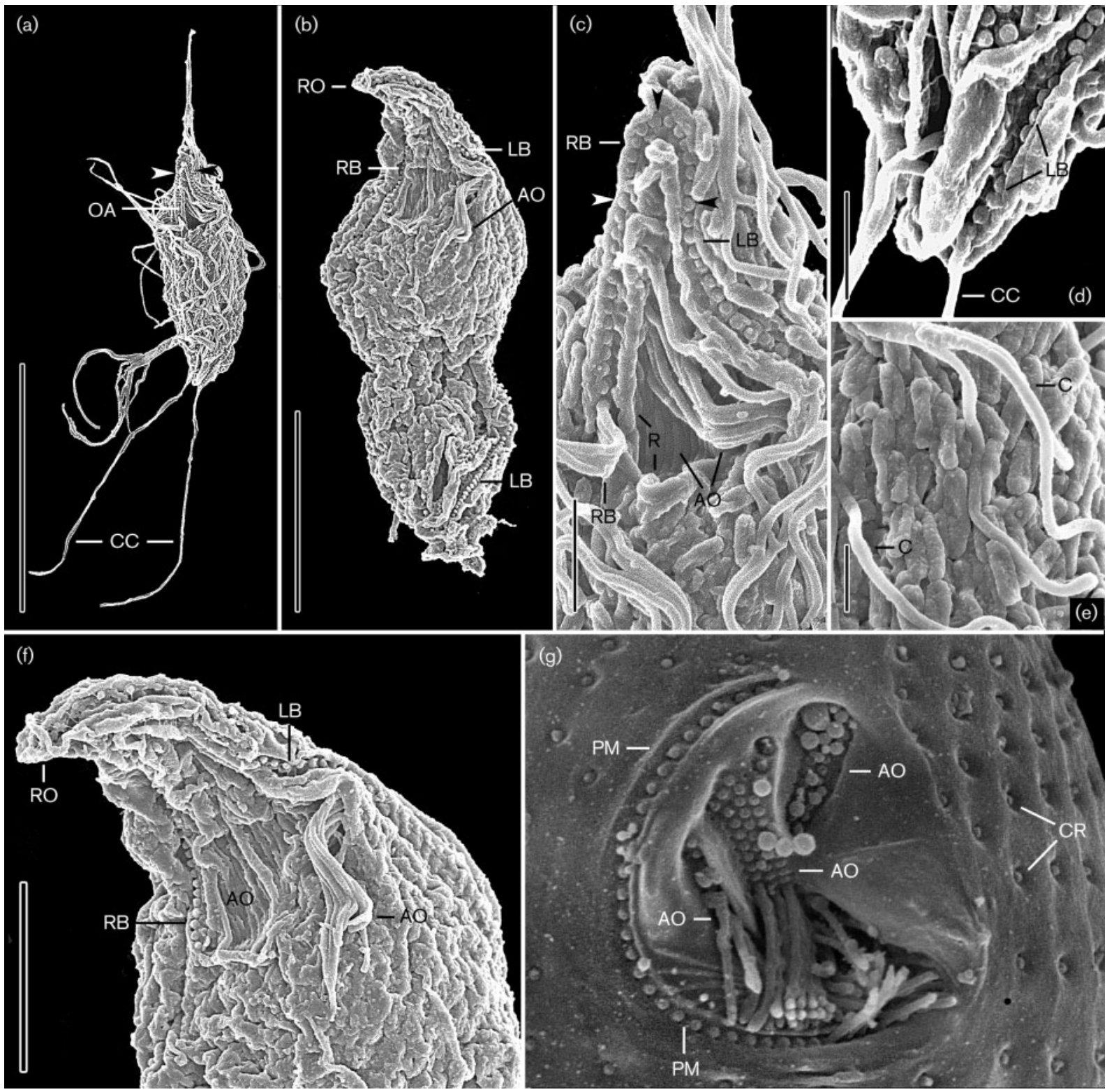

Fig. 2. (a-g) FISH-SEM micrographs of Cariacothrix caudata (a-f) and an ordinary SEM micrograph of a deciliated ciliate (g). $(a, c, d)$ Ventral overview and details from the anterior and posterior body region of the holotype specimen. The arrowheads in (a) mark the region shown in (c), i.e. the oral apparatus. The three arrowheads in (c) mark the apex of the archway kinety which is not interrupted, the most specific feature of the cariacotrichean ciliates. The caudal cilia arise from the last kinetids of the archway kinety $(a, d)$. (b, f) Lateral overview and detail, showing the rostrate anterior body region, the adoral organelles and the two branches of the archway kinety. (e) The ciliate's surface is densely covered by rod-shaped bacteria. (g) Oral region of a tetrahymenid ciliate. Note the similarity of paroral membrane and archway kinety. AO, Adoral organelles; $\mathrm{C}$, ordinary somatic cilia; CC, caudal cilia; CR, somatic ciliary row; LB, left branch of archway kinety; OA, oral apparatus; PM, paroral membrane; R, ridge; $\mathrm{RB}$, right branch of archway kinety; $\mathrm{RO}$, rostrum. Bars, $1 \mu \mathrm{m}(\mathrm{e}), 2 \mu \mathrm{m}$ (c, d, f), $10 \mu \mathrm{m}$ (b), $20 \mu \mathrm{m}(\mathrm{a})$. National Museum of Natural History (IJSNM) accession numbers: 1155310 (a, c, d) and 1155311 (b, g).

deposited in the Smithsonian Institution (National Museum of Natural History, Washington, DC, USA), under accession numbers 1155310, 1155311, 1155312, 1155313,1155314 and 1155315 . We declare the specimen shown in Figs $2 \mathrm{a}, \mathrm{c}, \mathrm{d}$ and $3 \mathrm{~b}$ as the holotype. It is contained on SEM stub 1155310.
Sequence data. The GenBank accession number for the partial 18S rRNA gene sequence of clone BCB5F14RJ2E06 is GU819615.

Description. In total, 14 specimens were located by scanning filters under epifluorescence using the $\mathrm{Cy} 3$ filter set, of which 

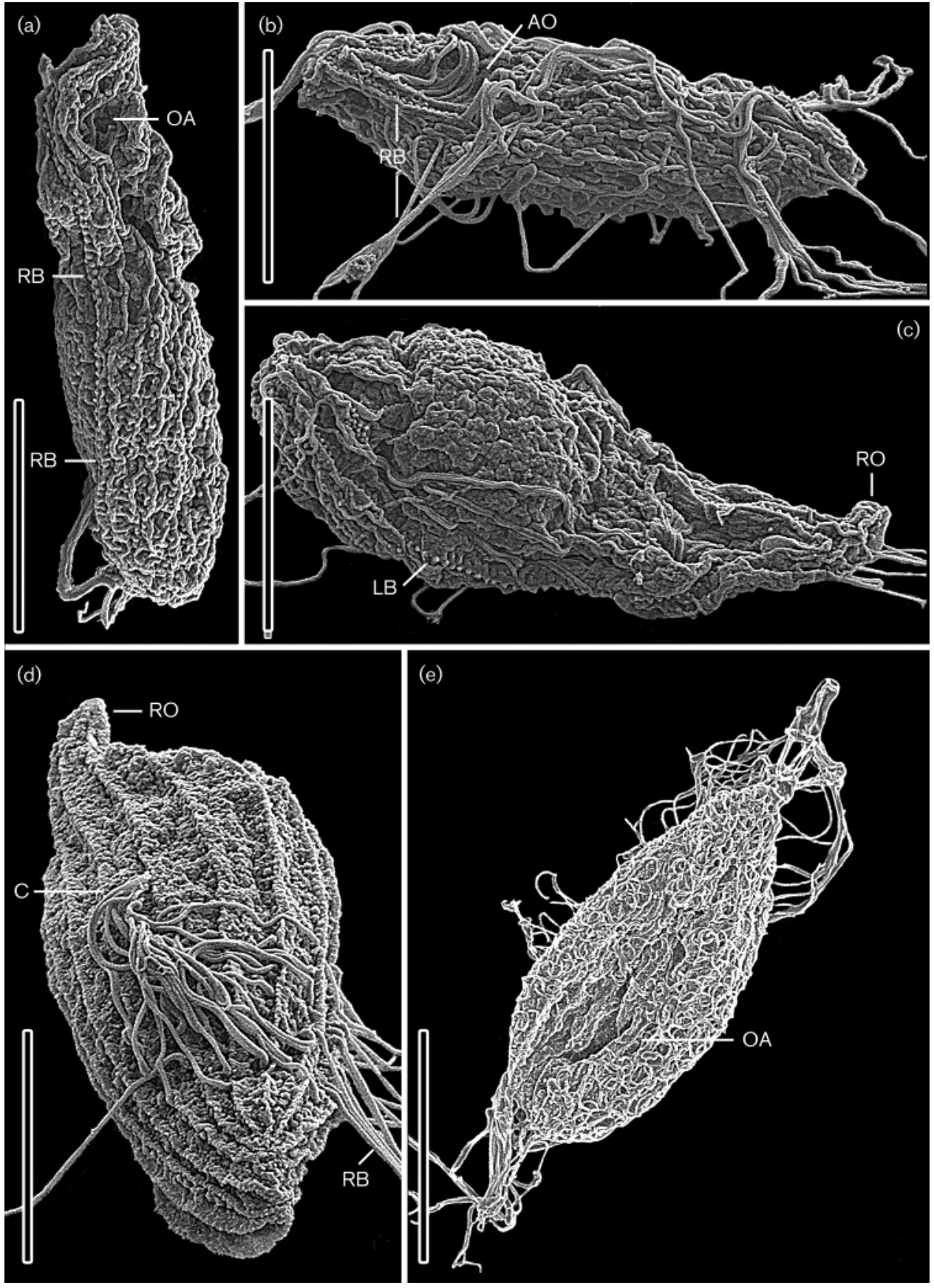

Fig. 3. (a-e) FISH-SEM micrographs of Cariacothrix caudata (a-d) and Cariacothrix sp. (e). (a, c) Ventral and lateral overviews, showing the two branches of the archway kinety extending whole body length (see also Fig. $2 \mathrm{a}-\mathrm{c}$ ). Note the rostrate anterior body region (c). (b) Lateral view of the holotype specimen, showing the flattened anterior body region and long cilia of the right branch of the archway kinety. (d) Right side overview, showing the dense ciliation. (e) Very likely, this is a second, slightly larger species, which is completely ciliated and has the oral apparatus ahead of mid-body. AO, Adoral organelles; $\mathrm{C}$, ordinary somatic cilia, LB, left branch of the archway kinety; OA, oral apparatus; RB, right branch of the archway kinety; RO, rostrum. Bars, $9 \mu \mathrm{m}$ $(\mathrm{a}, \mathrm{b}), 12 \mu \mathrm{m}$ (c, d, e). National Museum of Natural History (IJSNM) accession numbers: 1155310 (b), 1155312 (a), 1155313 (c), 1155314 (d), 1155315 (e). 


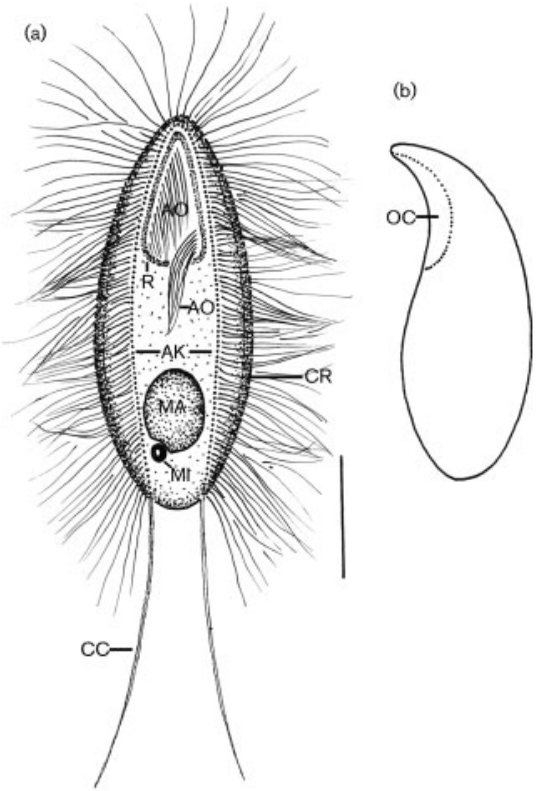

Fig. 4. Line drawings of Cariacothrix caudata, based on FISHSEM micrographs from 11 specimens. Length of cells about $30 \mu \mathrm{m}$. (a) Ventral view showing, inter alia, the densely ciliated archway kinety posteriorly ending in two long caudal cilia. (b) Side view showing the rostrate anterior body portion. AK, Archway kinety; AO, adoral organelles; CC, caudal cilium; CR, ordinary somatic ciliary row; MA, macronucleus; MI, micronucleus; OC, oral cavity; $\mathrm{R}$, ridge. Bar, $10 \mu \mathrm{m}$.
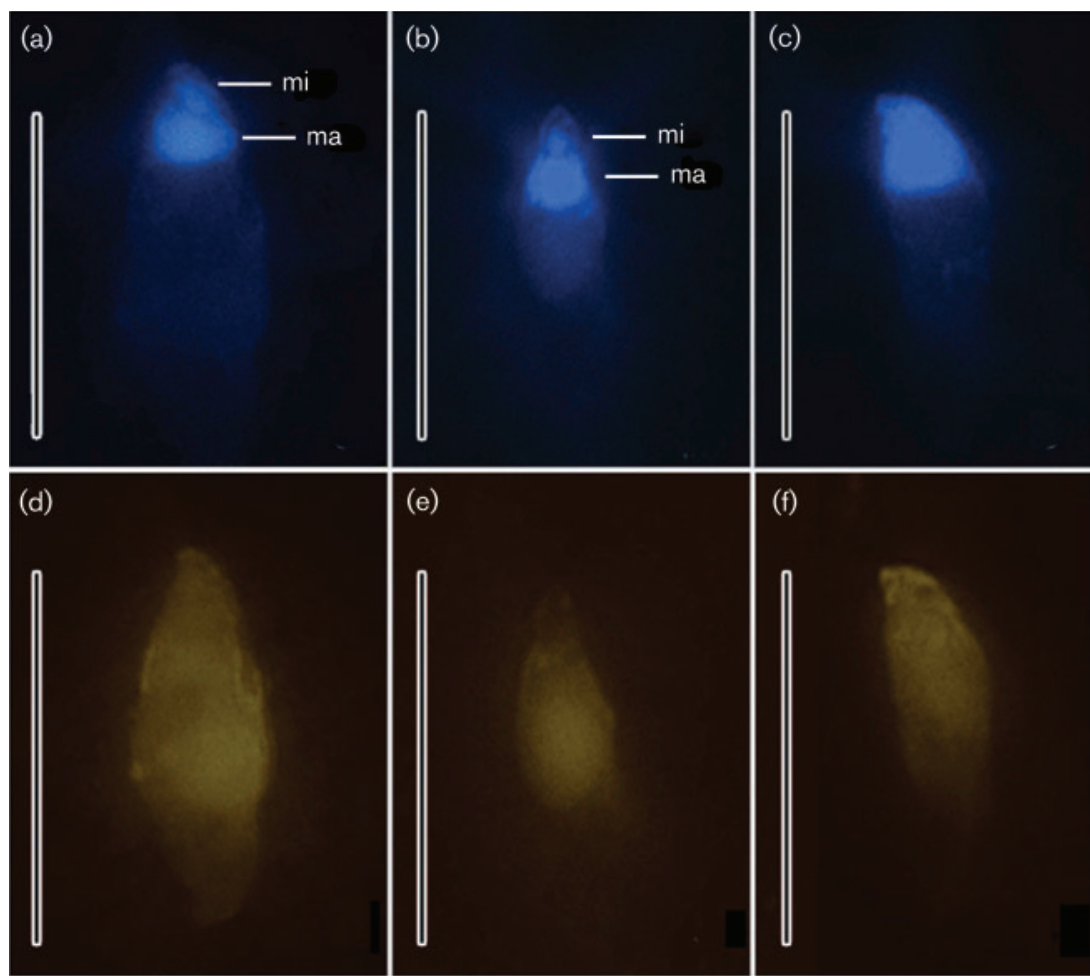

12 were useable; of these, 11 likely belong to Cariacothrix caudata, while one might be a different species (Fig. 3e). No cells were visible on filters stained with a nonsense probe.

The mean size of the FISH-labelled cells is $26.4 \times 9.8 \mu \mathrm{m}$ [median $26 \times 9.5$; SD 5 and 2.3; coefficient of variation (\%) 18.9 and 23.4; minimum 17 and 7; maximum 33 and 14; number of cells 12] after processing samples for FISH-SEM. Assuming a preparation shrinkage of $20 \%$ for the body, as is common in dehydrated cells, Cariacothrix caudata might have an in vivo size of about $32 \times 12 \mu \mathrm{m}$. When seen ventrally, the body is ellipsoidal to very bluntly fusiform, while it is slenderly ovate and rather distinctly rostrate in lateral view. The rostrate anterior third contains the oral cavity and is conspicuously flattened (Figs $4 \mathrm{a}, \mathrm{b}, 2 \mathrm{a}, \mathrm{b}, 3 \mathrm{a}-\mathrm{c}$, d and Movie S1). There is a single, ellipsoidal macronucleus and a globular micronucleus consistently in the posterior half of the body as visualized by DAPI staining (Figs $5 a-c$, 4a). In the SEM images, the cortex is almost completely covered by epibiotic bacteria approximately $1 \mu \mathrm{m}$ long (Fig. 2e and Movie S1). The cilia are 10 to $15 \mu \mathrm{m}$ long and $0.2 \mu \mathrm{m}$ thick, as typical for many ciliates; likely, they did not or only slightly shrink during preparation.

The ciliature has been rather poorly preserved, i.e. all cells lost most cilia. Fortunately, their basal bodies are recognizable. Actually, the specimens look like ciliates deciliated with a detergent, i.e. most cilia are lost but some remain (Fig. 2g). There are possibly 7-9 meridional ciliary rows (including the two branches of the archway kinety described below) laterally and dorsally, while the postoral
Fig. 5. DAPI $(a-c)$ and Cy3 $(d-f)$ staining of cariacotrichean ciliates from the deep anoxic portion of the Cariaco Basin visualized with the CARH658 FISH probe. ma, Macronucleus; mi, micronucleus. Bars, $30 \mu \mathrm{m}$. 


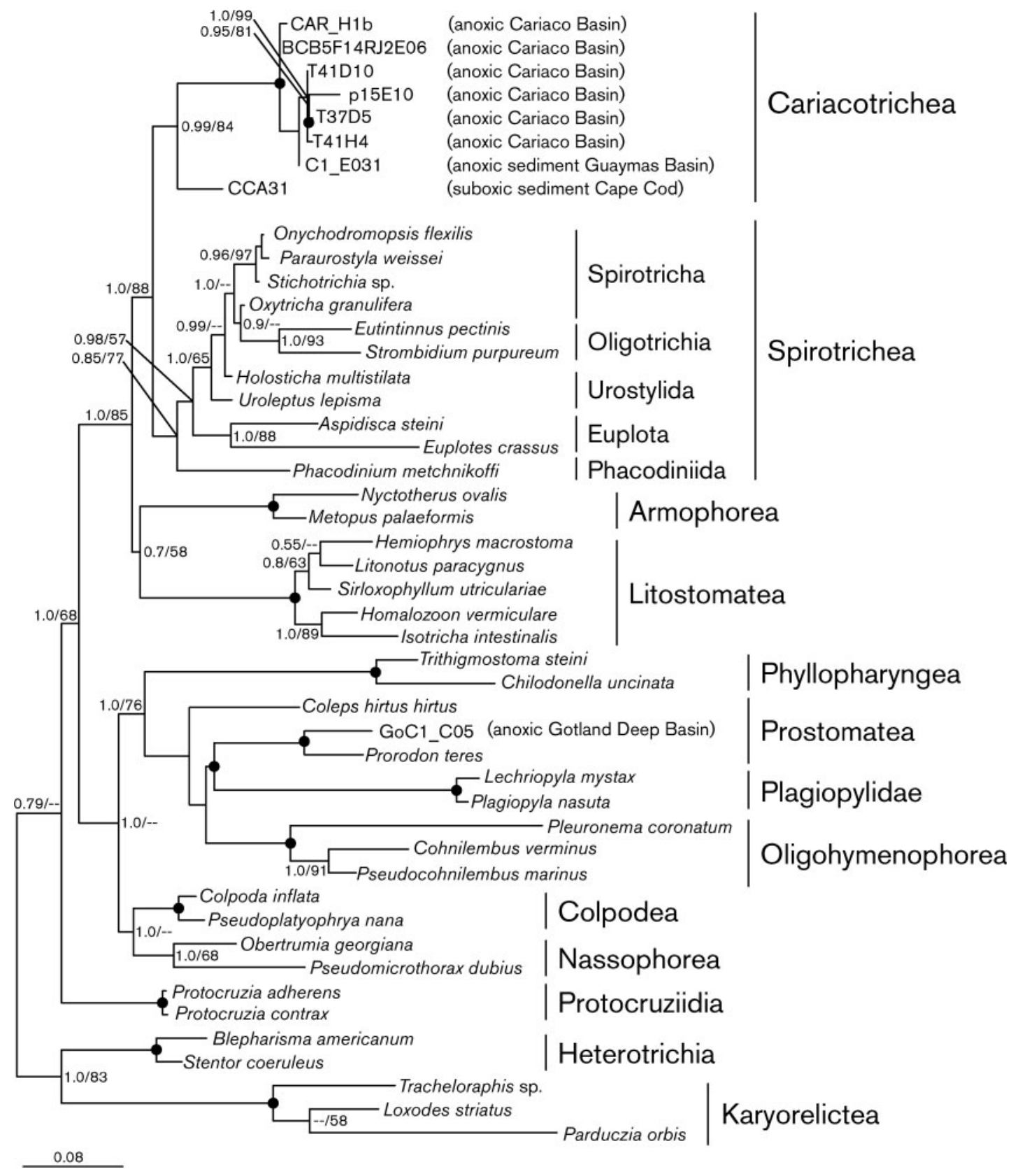

Fig. 6. Phylogenetic position of the ciliate class Cariacotrichea within the phylum Ciliophora, based on 18S rRNA gene sequences. Bootstrap (BT) and posterior probability (PP) values of $>50 \%$ are given the nodes in the order PP/BT. A black circle denotes full bootstrap and posterior probability support. Dashed lines represent a bootstrap or posterior probability value of less than $50 \%$ or 0.50 . The tree is based on an alignment of $942 \mathrm{nt}$ positions using the maximum-likelihood and Bayesian methods, respectively. Bar, 0.08 substitutions per nucleotide position.

region is very likely barren (Figs $4 \mathrm{a}, 2 \mathrm{~b}, 3 \mathrm{c}$ ). The most conspicuous structure is an archway-shaped ciliary row ('archway kinety') delineating the upper and lateral margin of the oral cavity, from where it extends to the posterior body end on both sides of the oral cavity. Each branch comprises about 70 very narrowly spaced basal bodies and ends with a 20 to $30 \mu \mathrm{m}$ long caudal cilium (Figs $2 \mathrm{a}-\mathrm{d}$, f, 3a, b and Movie S1). In a few specimens, small portions of the archway kinety are ciliated, showing that it is, indeed, a ciliary row (Figs 2c, 3d).

The oral apparatus occupies the anterior body third. The triangular oral opening is delineated by a shallow ridge. There are two adoral organelles recognizable: one is in the 
left posterior corner of the oral cavity and composed of about seven $8 \mu \mathrm{m}$-long cilia; the other organelle covers the bottom of the cavity and consists of 10-15 very narrowly spaced cilia (Figs 3a, b, 2a-c, f, 3a-c and Movie S1). We could not locate a 'typical' paroral membrane. However, the cilia that cover the bottom of the oral cavity could belong to a paroral dislocated by the preparation procedures. Alternatively, the archway kinety could be a highly modified paroral (see Fig. 2c, g).

The second species is holotrichously ciliated and possibly has elongated cilia at both ends of the cell. Further, the oral opening is more subapical than in Cariacothrix caudata (Fig. 3e).

Ecology. Cells were found to have an in situ abundance of 0.2 cells $\mathrm{ml}^{-1}$ at a depth of $900 \mathrm{~m}$ in the Cariaco Basin. This region of the basin is permanently anoxic and exhibits a concentration of hydrogen sulfide up to $53 \mu \mathrm{M}$ (Edgcomb et al., 2011a, b). This depth has a typical temperature of $17{ }^{\circ} \mathrm{C}$ and a salinity of $36.2 \%$.

\section{DISCUSSION}

In our phylogenetic analyses (Fig. 6), the class Cariacotrichea forms a clade that is fully supported by both maximum-likelihood and Bayesian methods, is affiliated with the ciliate subphylum Intramacronucleata, and does not phylogenetically nest within any of the eleven described classes of ciliates (Lynn, 2008). This suggests that the cariacotrichea represent a new class of ciliates, presumably restricted to anoxic marine environments. The microeukaryotic community in the Cariaco Basin has likely diversified and speciated in response to the biogeochemical gradients of oxygen and sulfide (Orsi et al., 2011). Thus, the unique geochemistry of anoxic environments may explain, in part, the divergent phylogenetic position and outstanding morphology of the class Cariacotrichea. The closest class to the class Cariacotrichea is the class Spirotrichea, branching as a sister clade with bootstrap and posterior probability support of $64 \%$ and 0.89 , respectively. The spirotricheans are a species-rich, rather diverse taxon, containing the oligotrichids, euplotids, stichotrichs and, possibly, the 'ribosubclasses' Protocruziidia, Phacodiniidia and Licnophoridia (Lynn, 2008). However, none of these closely resemble members of the class Cariacotrichea morphologically, which instead superficially looks similar to some hymenostomes, namely members of the genera Cyclidium, Tetrahymena and Wilbertia (Fan et al., 2009). Cells of the class Cariacotrichea also resemble those from the karyorelictean genera Loxodes and Remanella, which also have a rostrum and live anaerobically. However, these and all other described ciliates lack an archway-shaped kinety, as well as the cirrus-like organelle in the left posterior corner of the oral cavity.

\section{ACKNOWLEDGEMENTS}

We would like to thank the captain and crew of the B/O Hermano Ginés and the staff of the Fundación La Salle de Ciencias Naturales
(FLASA) for their assistance during our fieldwork in Venezuela, without whom this work would not be possible. We are also deeply grateful to Yrene Astor and Ramon Varela who were instrumental in the transportation of the DEEP-SID to and from Isla Margarita, as well as Gordon Taylor and Mary Scranton for their logistical support. We appreciate advice by Dr Rudolf Amann from the Max Planck Institute for Marine Microbiology in Bremen, Germany, on optimization of FISH probes in the absence of proper positive control. This research was supported by grants from NSF (MCB0348341 and DEB-0816840 to S.E., MCB-0348407 to V.E. and OCE 03-26175 to G.T.T.) and the Austrian Science Foundation to W.F. (FWF, P-20360-B17). This is a contribution no. 271 from the Marine Science Center, Northeastern University, Nahant, MA, USA.

\section{REFERENCES}

Abramoff, M. D., Magelhaes, P. J. \& Ram, S. J. (2004). Image processing with ImageJ. Biophotonics International 11, 36-42.

Alexander, E., Stock, A., Breiner, H. W., Behnke, A., Bunge, J., Yakimov, M. M. \& Stoeck, T. (2009). Microbial eukaryotes in the hypersaline anoxic L'Atalante deep-sea basin. Environ Microbiol 11, 360-381.

Behrens, S., Rühland, C., Inácio, J., Huber, H., Fonseca, A., SpencerMartins, I., Fuchs, B. M. \& Amann, R. (2003). In situ accessibility of small-subunit rRNA of members of the domains Bacteria, Archaea, and Eucarya to Cy3-labeled oligonucleotide probes. Appl Environ Microbiol 69, 1748-1758.

Edgcomb, V. P., Kysela, D. T., Teske, A., de Vera Gomez, A. \& Sogin, M. L. (2002). Benthic eukaryotic diversity in the Guaymas Basin hydrothermal vent environment. Proc Natl Acad Sci U S A 99, 7658-7662.

Edgcomb, V., Orsi, W., Bunge, J., Jeon, S. O., Christen, R., Leslin, C., Holder, M., Taylor, G. T., Suarez, P. \& other authors (2011a). Protistan microbial observatory in the Cariaco Basin, Caribbean. I. Pyrosequencing vs Sanger insights into species richness. ISME J 5, 1344-1356.

Edgcomb, V., Orsi, W., Taylor, G. T., Vdacny, P., Taylor, C. T., Suarez, P. \& Epstein, S. (2011b). Accessing marine protists from the anoxic Cariaco Basin. ISME J 5, 1237-1241.

Epstein, S. \& Lopez-Garcia, P. (2008). "Missing" protists: a molecular prospective. Biodivers Conserv 17, 261-276.

Fan, X., Miao, M., Al-Rasheid, K. A. S. \& Song, W. (2009). A new genus of marine scuticociliate (Protozoa, Ciliophora) from northern China, with a brief note on its phylogenetic position inferred from small subunit ribosomal DNA sequence data. J Eukaryot Microbiol 56, 577-582.

Finlay, B. J., Corliss, J. O., Esteban, G. \& Fenchel, T. (1996). Biodiversity at the microbial level: the number of free-living ciliates in the biosphere. Q Rev Biol 71, 221-237.

Foissner, W. (1991). Basic light and scanning electron microscopic methods for taxonomic studies of ciliated protozoa. Eur J Protistol 27, 313-330.

Foissner, W. (2003). Deciliation of ciliated protozoa for scanning electron microscopy: a fast, simple method using tensides. In Abstracts of the 4th European Congress of Protistology and 10th European Conference on Ciliate Biology, 31 August-5 September 2003, San Benedetto del Tronto (AP), Italy, p. 133.

Foissner, W., Agatha, S. \& Berger, H. (2002). Soil ciliates (Protozoa, Ciliophora) from Namibia (Southwest Africa), with emphasis on two contrasting environments, the Etosha region and the Namib Desert. Denisia 5, 1-1459.

Foissner, W., Chao, A. \& Katz, L. A. (2008). Diversity and geographic distribution of ciliates (Protista: Ciliophora). Biodivers Conserv 17, 345-363. 
Ludwig, W., Strunk, O., Westram, R., Richter, L., Meier, H., Yadhukumar, Buchner, A., Lai, T., Steppi, S. \& other authors (2004). ARB: a software environment for sequence data. Nucleic Acids Res 32, 1363-1371.

Lynn, D. H. (2008). The Ciliated Protozoa: Characterization, Classification, and Guide to the Literature, 3rd edn. New York: Springer.

Muller-Karger, F. E., Varela, R., Thunell, R., Scranton, M., Bohrer, R., Taylor, G. T., Capelo, J., Astor, Y., Tappa, E. \& other authors (2001). Annual cycle of primary production in the Cariaco Basin: Response to upwelling and implications for vertical export. Geophys Res 106 (C3), 4527-4542.

Orsi, W., Edgcomb, V., Jeon, S. O., Leslin, C., Bunge, J., Taylor, G. T., Varela, R. \& Epstein, S. (2011). Protistan microbial observatory in the Cariaco Basin, Caribbean. II. Habitat specialization. ISME J 5, $1357-$ 1373.

Posada, D. \& Crandall, K. A. (1998). MODELTEST: testing the model of DNA substitution. Bioinformatics 14, 817-818.

Ronquist, F. \& Huelsenbeck, J. P. (2003). MrBayes 3: Bayesian phylogenetic inference under mixed models. Bioinformatics 19, 15721574

Song, W., Warren, A. \& Hu, X. (editors) (2009). Free-living Ciliates in the Bohai and Yellow Seas, China. Beijing: Science Press.
Stamatakis, A., Hoover, P. \& Rougemont, J. (2008). A rapid bootstrap algorithm for the RAxML Web servers. Syst Biol 57, 758-771.

Stoeck, T., Fowle, W. H. \& Epstein, S. S. (2003a). Methodology of protistan discovery: from rRNA detection to quality scanning electron microscope images. Appl Environ Microbiol 69, 6856-6863.

Stoeck, T., Taylor, G. T. \& Epstein, S. S. (2003b). Novel eukaryotes from the permanently anoxic Cariaco Basin (Caribbean Sea). Appl Environ Microbiol 69, 5656-5663.

Stoeck, T., Hayward, B., Taylor, G. T., Varela, R. \& Epstein, S. S. (2006). A multiple PCR-primer approach to access the microeukaryotic diversity in environmental samples. Protist 157, 31-43.

Taylor, C. D. \& Doherty, K. W. (1990). Submersible Incubation Device (SID), autonomous instrumentation for the in situ measurement of primary production and other microbial rate processes. Deep-Sea Res 37, 343-358.

Taylor, C. D., Howes, B. L. \& Doherty, K. W. (1993). Automated instrumentation for time-series measurements of primary production and nutrient status in production platform-accessible environments. Mar Technol Soc J 27, 32-44.

Taylor, G. T., labichella, M., Ho, T.-Y., Scranton, M. I., Thunell, R. C., Muller-Karger, F. \& Varela, R. (2001). Chemoautotrophy in the redox transition zone of the Cariaco Basin: A significant midwater source of organic carbon production. Limnol Oceanogr 46, 148-163. 